\title{
EXPERIMENTAL STUDY OF THE SEISMIC PERFORMANCE OF PLASTERBOARD PARTITION WALLS WITH SEISMIC GAPS
}

\author{
Joshua G. Mulligan ${ }^{1}$, Timothy J. Sullivan² and Rajesh P. Dhakal $^{3}$
}

(Submitted September 2019; Reviewed October 2019; Accepted February 2020)

\begin{abstract}
It is now widely recognized that the performance of non-structural elements is crucial to the performance of building systems during earthquakes. Field surveys and experimental studies have shown that light steel or timber framed plasterboard partition walls are particularly vulnerable. The objective of this study is to investigate the seismic performance of a novel seismic gap partition system with angled return walls under quasi-static cyclic loading applied obliquely and to investigate the benefits of using acrylic gap-filler in the seismic gaps. Two specimens were tested: a steel stud specimen and a timber stud specimen. Observed drift capacities were significantly greater than traditional plasterboard partition systems. Equations were used to predict the drift at which damage state 1 (DS1) and damage state 2 (DS2) would initiate. The equation used to estimate the drift at the onset of DS1 accurately predicted the onset of plaster cracking but overestimated the drift at which the gap filling material was damaged. The equation used to predict the onset of DS2 provided a lower bound for both specimens and also when used to predict results of previous experimental tests on seismic gap systems. The gap-filling material reduced the drift at the onset of DS1, however, it had a beneficial effect on the re-centring behaviour of the linings. Out-of-plane displacements and return wall configuration did not appear to significantly impact the onset of plaster cracking in the specimens.
\end{abstract}

\section{INTRODUCTION}

It is now widely recognized that careful consideration of the performance of non-structural elements is crucial for the performance of buildings during earthquakes. Limiting damage to non-structural elements is vital to maintain the continuity of emergency and recovery services, to reduce the likelihood of injury or death, to prevent loss of building function, and to limit the direct and indirect economic losses resulting from earthquake events. Taghavi and Miranda [1] and Khakurel et al. [2] have shown that non-structural elements comprise the majority of investment in commercial buildings (Figure 1) and that interior construction, which includes partitions, doors, wall finishes, ceilings, and floor finishes, comprises $20-30 \%$ of the non-structural component cost. Partition walls, also known as drywalls, have been shown to significantly contribute to total earthquake losses [3, 4]. Whitman et al. [5] found that in the 1971 San Fernando Earthquake, for buildings in earthquake intensity (MMI) zones VI, VII, and VIII, the damage to partitions was approximately 90,65 , and $50 \%$ respectively of the total cost of damage to buildings. They concluded that improving the seismic performance of interior partitions would be one of the most effective ways to reduce the seismic losses in buildings subjected to MMI VI earthquakes [5]. This is because partition walls are particularly susceptible to earthquake damage, with the onset of damage initiating at low interstorey drifts of approximately $0.35 \%$ [6]. This level of interstorey drift may be imposed by low intensity ground motions with small return periods and this implies frequent repairs after relatively small earthquake events or aftershocks, resulting in significant financial loss $[4,7]$. This was observed in many buildings following the 4th September 2010 Darfield (Canterbury) earthquake, where aftershocks caused new cracks on walls and internal linings to develop and existing cracks to widen and extend [8]. Following the 22 February 2011
Christchurch Earthquake Baird et al. [9] suggested that the repeated damage to partitions from aftershocks, which exceeded the serviceability limit state, implies that current code requirements do not set a high enough threshold for damage avoidance in order to minimize economic loss.

The earliest experimental investigations on gypsum lined walls were focused on the load-deformation of shear walls designed to resist lateral loads [10-12]. However, in order to inform the calibration of models in performance-based earthquake engineering, modern studies began to focus on the damage and repair cost of non-structural partition systems. Lee et al. [13] tested full-scale partitions with lightweight steel framing according to typical Japanese configurations and estimated a damage-repair cost relationship. Overall, the specimens in this study were damage free up to $0.25 \%$ interstorey drift. Restrepo and Bersofsky [14] tested partition wall specimens built according to typical US configurations using the damage state (DS) definitions as provided by Taghavi and Miranda [1] These damage state definitions are as follows: DS1, cracking in plaster and paint; DS2, damage to drywall panels; and DS3, damage to framing. For the conventional steel stud partitions tested by Restrepo and Bersofsky [14] DS1, DS2, and DS3 occurred at drifts of $0.3 \%, 1.0 \%$, and $3.0 \%$ respectively.

Although significant research has been conducted on the behaviour of non-structural partition walls subject to in-plane deformations, their behaviour when subjected to out-of-plane displacements has not been studied previously. Previous studies have mainly focused on the out-of-plane behaviour of partitions when subject to acceleration [6, 15]. Petrone et al. [16] conducted quasi-static tests on a single vertical "strip" of wall. This carries the assumption that the wall is wide enough in order to neglect the influence of adjacent return walls. In addition, the out-of-plane displacements were applied in a sixpoint bending scheme and therefore simulated displacements

\footnotetext{
1 Corresponding Author, Master's Student, University of Canterbury, Christchurch, joshua.mulligan@pg.canterbury.ac.nz

2 Professor, University of Canterbury, Christchurch, timothy.sullivan@canterbury.ac.nz (Member)

3 Professor, University of Canterbury, Christchurch, rajesh.dhakal@canterbury.ac.nz (Fellow)
} 


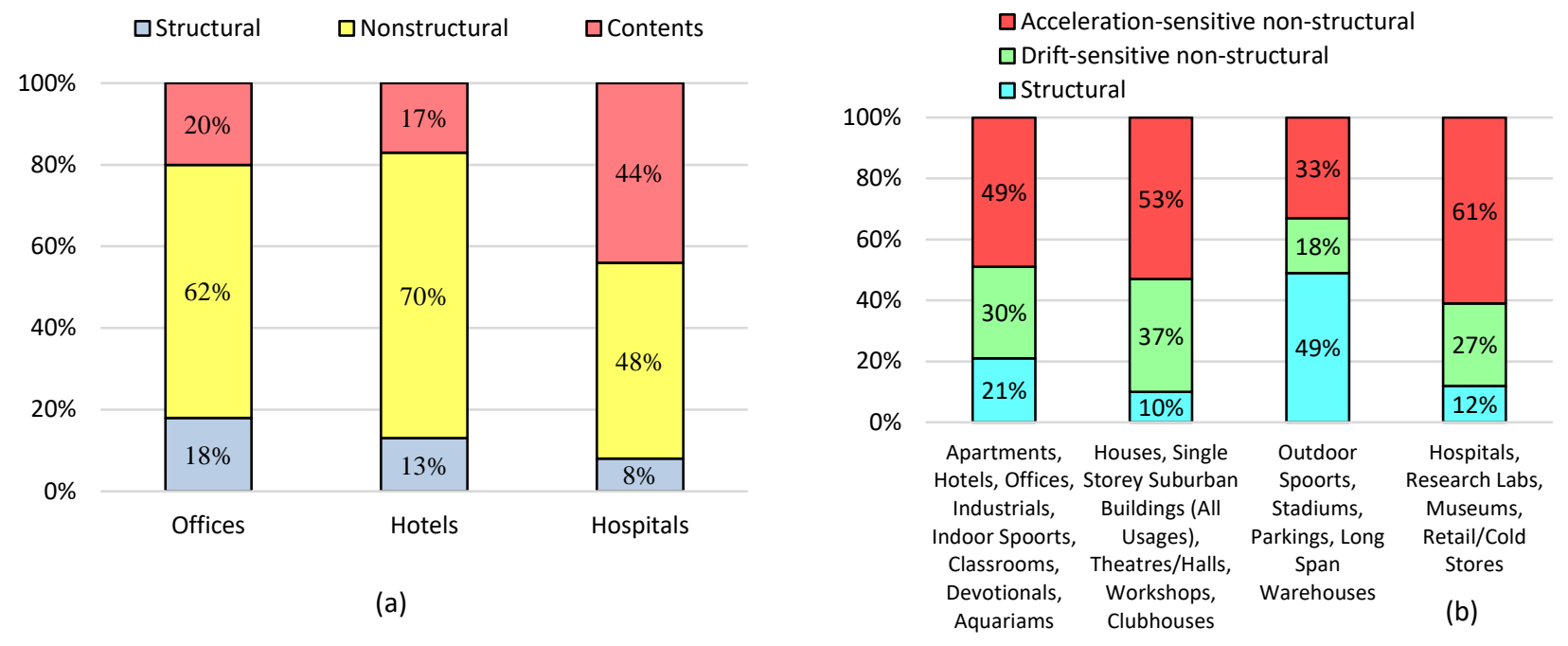

Figure 1: Building construction cost distribution of different buildings from (a) Taghavi and Miranda [1] and (b) Khakurel et al. [2].

induced by out-of-plane accelerations rather than interstorey drift.

Davies et al. [6] conducted an extensive series of experiments into the seismic performance of plasterboard partition walls. The authors tested 50 full scale partition walls in 22 different configurations under both quasi-static and dynamic loading and generated data regarding the in- and out-of-plane seismic behaviour. Variables included return wall configurations; partial-height and full-height specimens; alternate junction details; connectivity of studs, tracks, and sheathing; and bookshelf attachments. This data was used to produce a set of fragility parameters, useful for implementation in Performance Based Earthquake Engineering (PBEE) analysis of buildings. For the development of the fragility parameters, the authors used damage states previously defined by Taghavi and Miranda [1]. For the test specimens most like NZ commercial partitions, the mean drift associated with DS1, DS2, and DS3 was $0.26 \%$, $0.68 \%$, and $0.75 \%$ respectively. It should be noted that DS3 was triggered at relatively low drifts. This was due to failure in the track to concrete fasteners, not observed in the tests of Restrepo and Bersofsky [14] or Lee et al. [13].

Included within the test series of Davies et al. [6] were some novel details for improving the performance of partitions, including a 'sacrificial corner bead' system and a flexible track system. A similar system to this flexible track system was also tested in Mulligan et al. [17]. Other systems have been proposed in the literature for the improvement of the seismic performance of partitions: including a sliding/frictional system developed by Araya-Letelier and Miranda [18], and a seismic gap system tested in several studies [13, 19, 20, 21, 22]. The seismic gap system tested by Tasligedik et al. [20] offered a DS1 drift capacity of over $2.0 \%$.

The seismic gap specimen details suggested by Tasligedik et al. [20] included fire and non-fire rated alternatives. These details are as shown in Figure 2. At the horizontal boundary the external studs were attached to the frame but not to the linings; and an additional stud was provided near the external stud to which the linings were attached so that the linings and internal framing are free to slide within the bottom and top tracks. As the specimens tested in by Tasligedik et al. [20] did not include any specimens with return walls and displacements were applied in-plane only, these details have not been verified for their out-of-plane performance or considering the interaction with return walls. The objective of this study therefore is to investigate the behaviour of partition systems with seismic gaps in configurations that have not previously tested: as an internal partition, without bounding structural members; in a unique yshape configuration; with one return wall at a $45^{\circ}$ angle; and under a quasi-static cyclic loading protocol applied obliquely. In addition, the impact of using a filler material in the seismic gaps is to be investigated.

\section{EXPERIMENTAL TESTS IN THIS STUDY}

\section{Specimen Design}

The specimen designs in this study are a variation on the designs detailed in Tasligedik et al. [20], further adapted in this work following discussions and proposals from an industry collaborator. The details proposed by Tasligedik et al. [20] were for infill walls and thus had to be converted to equivalent details for internal partitions walls with no structural boundaries. In particular, the junction details were modified by connecting tracks to the returns and friction fitting the studs within these. Top and bottom track anchors were removed in the proximity of junctions at some locations to allow the tracks to bend. The wallboards were also fitted hard to the floor. The intermediate top and side edges at gap locations were finished with GIB ${ }^{\circledR}$ Goldline ${ }^{\circledR}$ L-Trim. The gaps were also half-filled with GIB ${ }^{\circledR}$ Gap Filler in order to assess the benefits of using filler to improve the aesthetic as an alternative to negative detailing.

The configuration chosen to provide a baseline for the specimens was a fire rated partition typology selected from GIB Fire Rated Systems [23] with a 60 minute fire-resistance rating (GBS60). Two specimens were constructed: a steel stud specimen with a total nominal horizontal gap size of $10 \mathrm{~mm}$ provided by two nominal $5 \mathrm{~mm}$ gaps at each end (details shown Figures 3, 5, and 6); and a timber stud specimen with a total nominal horizontal gap size of $25 \mathrm{~mm}$ provided by two nominal $10 \mathrm{~mm}$ gaps at each end and an additional nominal $5 \mathrm{~mm}$ gap in an intermediate joint (details shown in Figures 4, 5, and 6). The steel stud specimen framing consisted of $92 \times 0.55 \mathrm{bmt}$ studs, $92 \times 0.5$ bmt stud tracks, and $92 \times 1.15$ bmt deflection head tracks. The timber stud specimen's framing materials were identical however $90 \times 45$ timber studs were used instead of 92 x $0.55 \mathrm{bmt}$ steel studs. For both specimens the framing was sheathed with $13 \mathrm{~mm}$ GIB Fyreline ${ }^{\circledR}$ connected to the framing with $25 \mathrm{~mm}$ x $6 \mathrm{~g}$ GIB Drywall Self Tapping Screws ${ }^{\circledR}$ at 300 $\mathrm{mm}$ centres up each stud. Bottom and top tracks were fixed to the top and bottom floor slabs with HILTI HUS3-H 8 × 55 screw anchors at $600 \mathrm{~mm}$ centres and were left out at some locations as shown. 

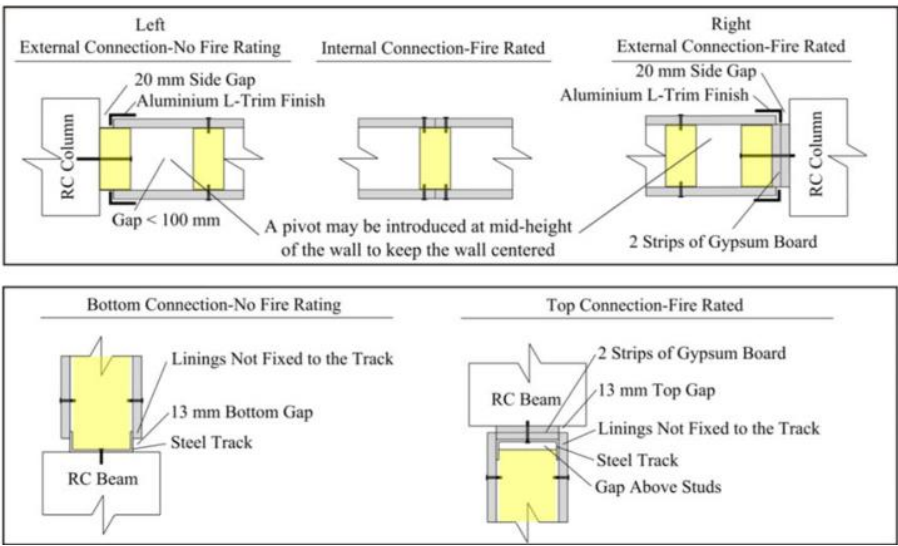

Figure 2: Details of low damage timber or steel framed specimens from Tasligedik et al. [20].

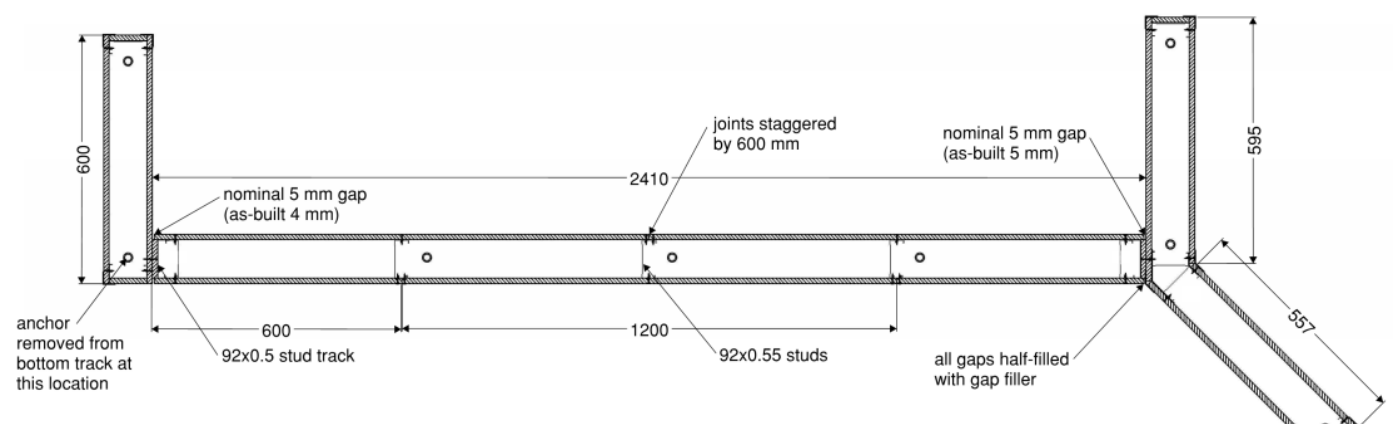

Figure 3: Specimen 1 plan - steel stud wall with no intermediate joints.

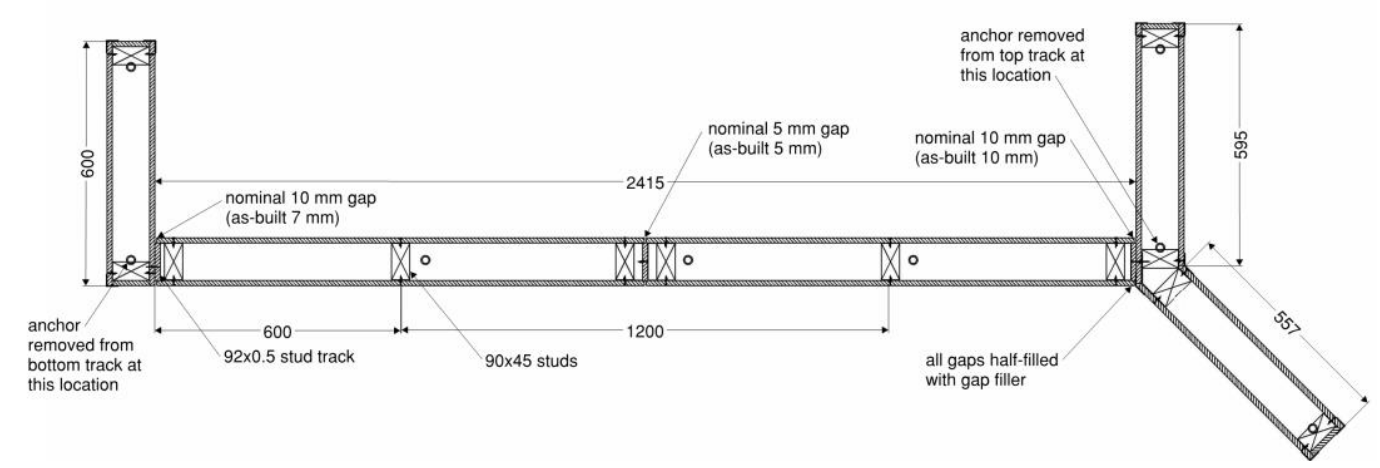

Figure 4: Specimen 2 plan - timber stud wall in steel tracks with intermediate joints.

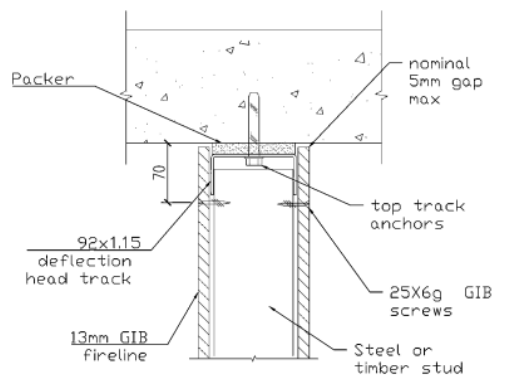

(a)

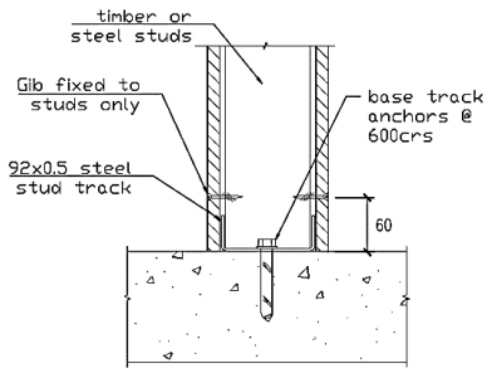

(b)

Figure 5: (a) Top slab to track connection (b) Bottom slab to track connection. 


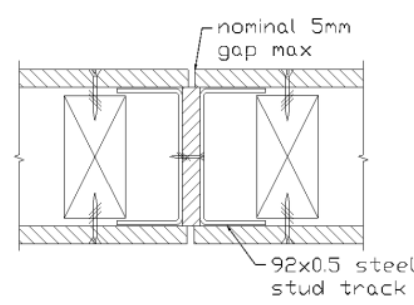

(a)

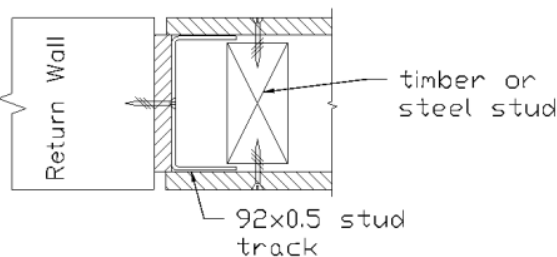

(b)

Figure 6: Details of modifications to Tasligedik et al. [20] low damage system (a) intermediate joint detail for Specimen 2 (b) Studs fit within steel tracks at junction for both specimens.

(1)

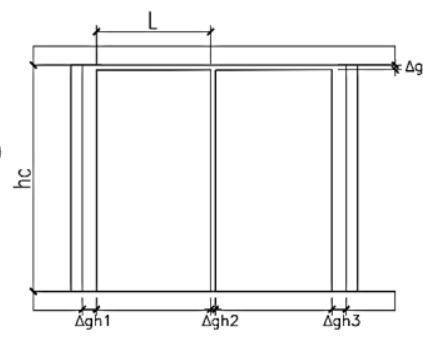

(2)

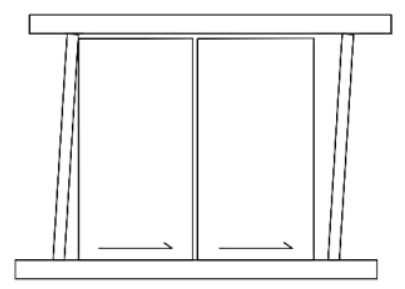

(3)

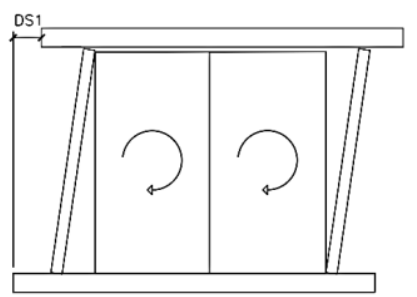

(4)

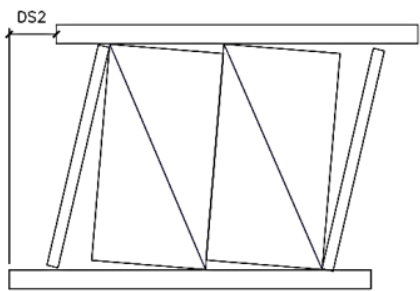

Figure 7: Predicted in-plane behaviour of specimens demonstrating estimated lower bound drift capacities for DS1 and DS2.

\section{Anticipated Capacity}

The in-plane behaviour of the specimens can be predicted assuming that the framing is free to slide within the tracks and that the linings behave as rigid bodies (Figure 7). The anticipated in-plane drift capacity for each specimen can be calculated from Equations 1 and 2 as per the deformation behaviour shown in Figure 7.

$D_{1}=\frac{\Delta_{G h}}{h_{c}} \times 100 \%$

$D_{2}=D_{1}+\frac{\Delta_{G v}}{L} \times 100 \%$

Where $D_{1}$ and $D_{2}$, are the design lower bound interstorey drift capacity for the damage state 1 and 2 respectively, $\Delta_{G h}$ is the sum of the horizontal gaps along the wall, $\Delta_{G v}$ is the sum of the vertical gap along the wall between the linings and the top and bottom floors, $h_{c}$ is the clear height between floors $(2405 \mathrm{~mm})$, and $L$ is the largest length of panel between joints along the wall. As there is a vertical gap between the linings and floor slab, the linings are able to undergo an additional interstorey drift before a strut will form. It is expected that wallboard damage will take place after the drift calculated from Equation 2 is reached, acknowledging that some of this capacity may be used up by vertical floor deflections. If significant floor deflections are expected this should be accounted for by reducing $\Delta_{G v}$ accordingly. For specimen 2 the length of panel between joints is reduced due to the presence of an intermediate joint and so it is anticipated that this will increase the drift at which DS2 occurs relative to a wall with gaps only at the ends. The specified gap sizes varied slightly from the design drawings, highlighting the need to allow for construction tolerances. Only the design drift capacities calculated using the as-built dimensions are shown are shown in Table 1.
Table 1: Estimated lower bound drift capacities, Di, from asbuilt gap sizes.

\begin{tabular}{ccccc} 
Specimen & $\begin{array}{c}\boldsymbol{\Delta}_{G \boldsymbol{h}} \\
(\mathbf{m m})\end{array}$ & $\begin{array}{c}\boldsymbol{\Delta}_{G \boldsymbol{v}} \\
(\mathbf{m m})\end{array}$ & $\boldsymbol{D}_{\mathbf{1}}(\boldsymbol{\%})$ & $\boldsymbol{D}_{\mathbf{2}}(\boldsymbol{\%})$ \\
\hline 1 - Steel Stud & 9 & 5 & 0.37 & 0.58 \\
2 - Timber Stud & 22 & 10 & 0.91 & 1.75 \\
\hline
\end{tabular}

As the plasterboard linings is not directly fixed to the steel tracks at the top or bottom, it is predicted that the plasterboard and internal framing will be free to rotate as the top boundary is displaced. As the mid-height of the wall is composite steel and gypsum board it will be significantly stiffer out-of-plane compared with the top and bottom ends of the wall. Therefore, it is anticipated that the gypsum board and the steel tracks will deform locally at the ends of the walls allowing the internal frame to rotate. The predicted large displacement behaviour of the wall is shown in Figure 8. The out-of-plane behaviour will

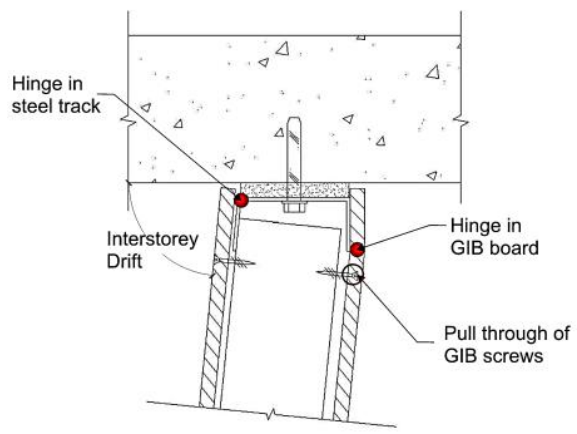

Figure 8: Predicted out-of-plane damage at large drift levels at the top and bottom interfaces. 


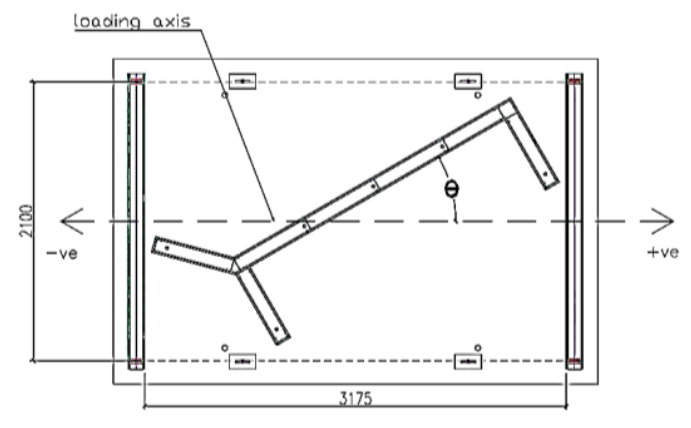

(a)

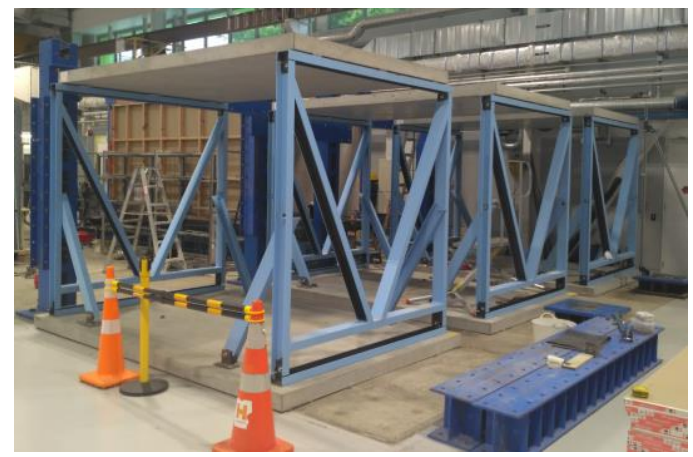

(c)

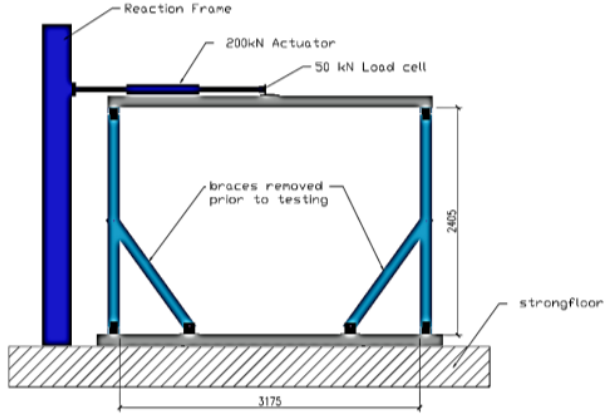

(b)

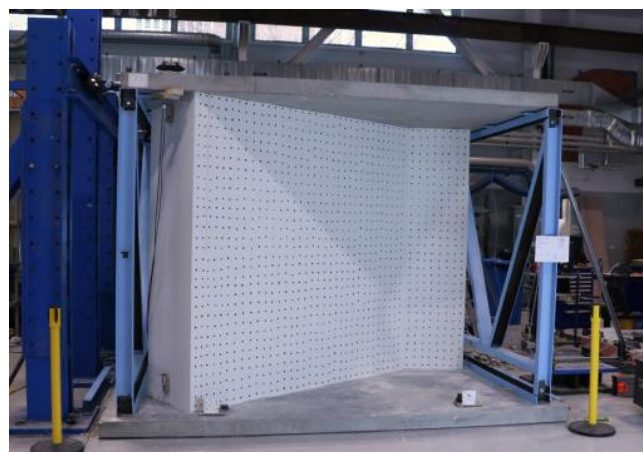

(d)

Figure 9: (a) Plan of testing frame (mm); (b) Elevation of testing frame (mm); (c) Photograph of setup; (d) Photograph of setup with specimen 1 installed.

also be influenced by the return walls and the bending of the tracks. However, the interaction between walls loaded out-ofplane and walls loaded in-plane is complex and difficult to simplify by mechanistic models.

\section{EXPERIMENTAL TEST SETUP}

\section{Testing Frame}

The walls were tested in racking in order to simulate the seismic loading experienced by internal partition walls in commercial buildings. The testing support frames (Figure 9) were hinged at the top and the bottom in the direction of actuator movement, with diagonal braces to provide stability while the actuator was not attached. The frames were constructed of steel 125 PFC members. The top and bottom concrete boundaries were 120 $\mathrm{mm}$ thick reinforced concrete. This slab was selected in order to simulate the most typical boundary conditions and flooring systems in real buildings. The plan dimensions of concrete space available to construct the partitions was $3175 \mathrm{~mm}$ by $2100 \mathrm{~mm}$, and the clear height was $2405 \mathrm{~mm}$. The response of the bare frame (Figure 10) was approximately linear with a stiffness of $10.1 \mathrm{~N} / \mathrm{mm}$.

\section{Experimental Program}

The specimens were tested according to the FEMA 461 deformation-controlled unidirectional quasi-static cyclic protocol [24]. The protocol was calibrated based on the results of previous in-plane tests for standard partition detailing using the tests by Restrepo and Bersofsky [14]. The estimated drift for DS1 was $0.3 \%$ and the target maximum drift was $5 \%$. Two cycles are performed at each loading amplitude. The amplitude of each step is 1.4 times the amplitude of the preceding step.

A total of sixteen loading steps were performed, up to a magnitude of $6.21 \%$, which corresponds to a maximum in- plane drift of $5.09 \%$ for walls angled at $35^{\circ}$ (Figure 11). To assess the impact of bidirectional demands on fragility, the wall specimens were aligned at an angle of $35^{\circ}$ to the loading direction, as shown in Figure 9a.

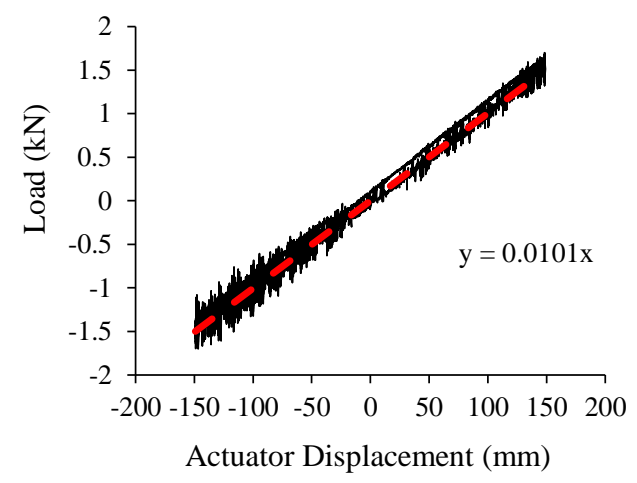

Figure 10: Load displacement behaviour of the bare frame.

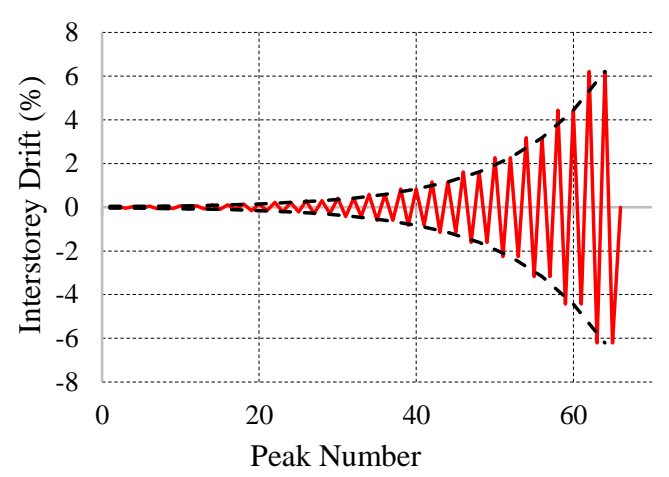

Figure 11: FEMA 461 quasi-static cyclic displacement protocol used in these tests. 


\section{Data Acquisition}

The load applied to the specimens was recorded from a $50 \mathrm{kN}$ load cell with an accuracy of $\pm 3 \mathrm{~N}$. The specimens were instrumented with a combination of linear potentiometers and a camera. Potentiometers were used to measure the horizontal, vertical and lateral deflections for both specimens. Specimen 1 used 26 potentiometers and specimen 2 used 29. The instrumentation layout is shown in Figure 13 with reference to the location shown in Figure 12. A series of high contrast points at approximately $75 \mathrm{~mm}$ spacing were applied to the surface of the specimens and the camera took pictures of these surfaces at each displacement increment in order to allow particle tracking analysis.

\section{RESULTS AND DISCUSSIONS}

\section{Damage Observations}

Damage observations were taken after each step in the loading protocol (Figure 11) and these relied upon visual inspections, physical marking of observed damage, notes, and photographs.

As only external visual observations could be made, the point at which the framing was damaged could not be identified unless the wallboard began to spall or if sufficient gap sizes developed at joints, which was only the case during the larger cycles. Therefore, the drifts recorded for DS3 correspond to instances in which framing damage could first be observed from visual inspection. Noting that while determining DS3 based on visual observations would be consistent with post-earthquake inspection processes, damage to internal framing may be discovered during repair works for DS2. The forms of damage observed during the tests are summarised in Table 2, along with their associated repair actions. Figure 14 illustrates the damage states being referred to in Table 2. These are similar to the damage state definition defined by Taghavi and Miranda [1] and include gap-filler debonding as part of DS1. The point at which the gap filler had debonded was chosen as the point at which the material had fully debonding through the whole depth, and/or was not able to be restored to its original appearance by repainting.

The drift in-plane to the long wall at which each damage state initiated in the specimens is shown in Table 3, along with the lower bound predictions for DS1 and DS2. Note that for specimen 2, DS1 initiated due to separation of the gap-filling material at a lower drift than the predicted. However, plaster damage occurred at $0.94 \%$ drift which is above the predicted value as expected.

Very little screw connection damage (DS1c) was observed during the test, in particular no popping or pull-through of the fastener heads was observed. The only form of screw connection damage observed was seen during the final loading step of both tests, where at some locations the sheathing had detached from the studs (Figure 14d). This occurred primarily along the top and bottom of the boundary studs of the long wall.

An additional form of damage was excessive gap size developing at the junction between the long wall and the returns (DS2b). To maintain fire rating at gap locations the linings must overlap the vertical strip of gypsum board by more than $6 \mathrm{~mm}$ (according to advice from an industry collaborator). Thus, the linings must be repositioned if the gaps grow such that the required cover is not provided.

Only at the completion of the test could a detailed inspection of the framing be made, the results of which are shown in Table 4 .
This value represents the length of undamaged framing at the end of the test as a percentage of the total original length of framing. Damage to the studs was concentrated at the ends of walls and near the junctions. Damage to the tracks was concentrated along the top with more deformation near junctions.

Table 2: Damage states.

\begin{tabular}{|c|c|c|}
\hline $\begin{array}{l}\text { Damage } \\
\text { State }\end{array}$ & Description & Repair Action \\
\hline 0 & $\begin{array}{l}\text { Hairline } \\
\text { cracking of } \\
\text { paint at joints }\end{array}$ & $\begin{array}{l}\text { Barely visible damage } \\
\text { deemed not requiring repair. }\end{array}$ \\
\hline 1.a & $\begin{array}{l}\text { Sealant de- } \\
\text { bonding }\end{array}$ & $\begin{array}{l}\text { Remove and re-apply gap } \\
\text { filler }\end{array}$ \\
\hline 1.b & $\begin{array}{l}\text { Cracking in } \\
\text { plaster and paint } \\
\text { along trim }\end{array}$ & $\begin{array}{l}\text { Scrape out minor cracks and } \\
\text { reapply plaster and paint. }\end{array}$ \\
\hline 1.c & $\begin{array}{l}\text { Screw damage - } \\
\text { pull through, } \\
\text { popping, or } \\
\text { shearing }\end{array}$ & $\begin{array}{l}\text { Re-fix or tighten any } \\
\text { existing loose fasteners and } \\
\text { place additional fasters near } \\
\text { original. Finish with plaster, } \\
\text { and sand and paint. }\end{array}$ \\
\hline 2.a & $\begin{array}{l}\text { Wallboard } \\
\text { damage - paper } \\
\text { face separating, } \\
\text { crushing, } \\
\text { cracking, or } \\
\text { spalling }\end{array}$ & $\begin{array}{l}\text { Requires replacement of } \\
\text { linings or local repairs of } \\
\text { linings. Breakages can be } \\
\text { ground out and patch fixed, } \\
\text { using plastering and paper } \\
\text { tape. }\end{array}$ \\
\hline 2.b & $\begin{array}{l}\text { Residual gap at } \\
\text { joints }\end{array}$ & Replace linings \\
\hline 3 & $\begin{array}{l}\text { Framing } \\
\text { damage - } \\
\text { flanges bent, } \\
\text { buckling, or } \\
\text { hinging }\end{array}$ & $\begin{array}{l}\text { Both linings and framing } \\
\text { must be removed and } \\
\text { replaced. Thus, complete } \\
\text { demolition and replacement } \\
\text { of the wall is required. }\end{array}$ \\
\hline
\end{tabular}

Table 3: In-plane drift (\%) at onset of damage.

Specimen 1 Specimen 2

\begin{tabular}{ccccc}
\hline DSi & Predicted & Observed & Predicted & Observed \\
\hline $\mathbf{1}$ & 0.37 & 0.48 & 0.91 & 0.67 \\
$\mathbf{2}$ & 0.58 & 0.94 & 1.74 & 1.86 \\
$\mathbf{3}$ & - & 2.6 & - & 3.64 \\
\hline
\end{tabular}

Table 4: Percentage of framing undamaged at the end of testing.

\begin{tabular}{cccc} 
Test & Studs & $\begin{array}{c}\text { Top } \\
\text { track }\end{array}$ & $\begin{array}{c}\text { Bottom } \\
\text { track }\end{array}$ \\
\hline B1 & $36 \%$ & $71 \%$ & $57 \%$ \\
B2 & $92 \%$ & $86 \%$ & $29 \%$ \\
\hline
\end{tabular}




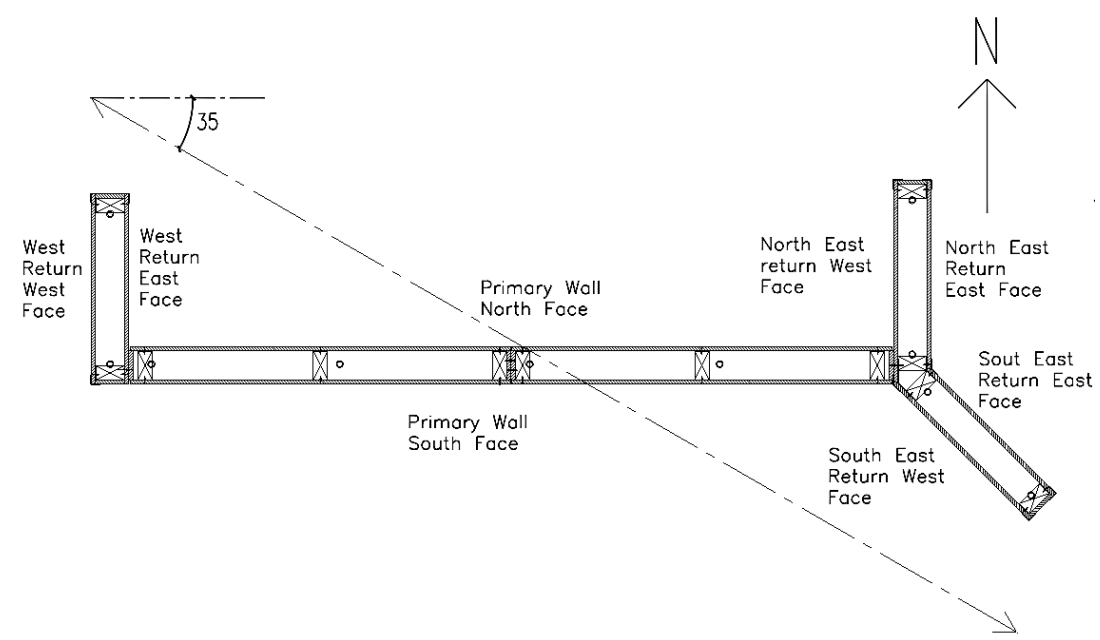

Figure 12: Wall specimen showing references for wall locations.

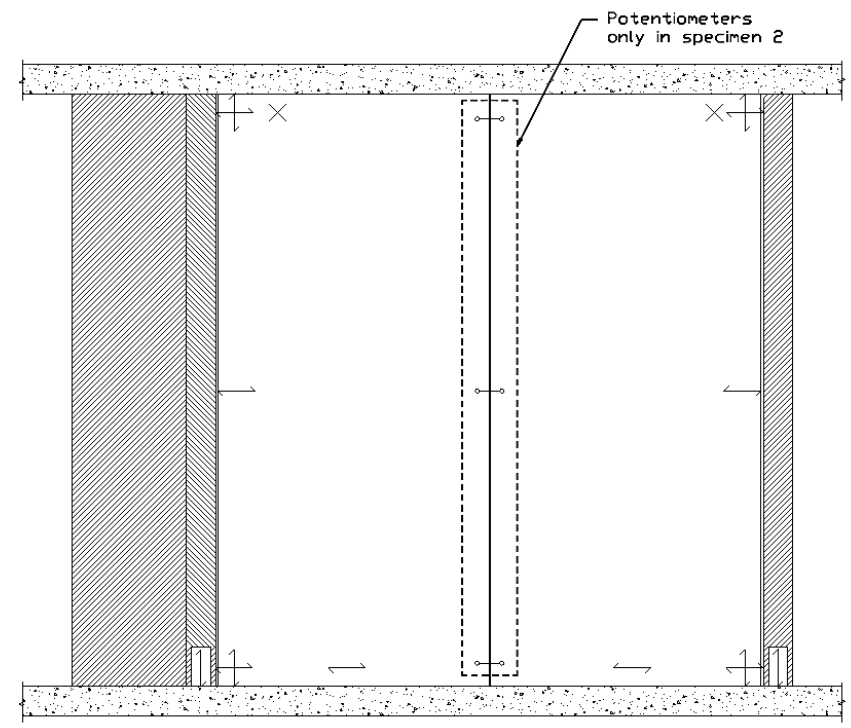

$X$ Linear potentiometer out of plane

$\hookrightarrow$ Linear potentiometer in-plane horizontal

$\int$ Linear potentiometer in-plane vertical

- relative displacement between wall sections - relative displacement between
wall and slab

(a)

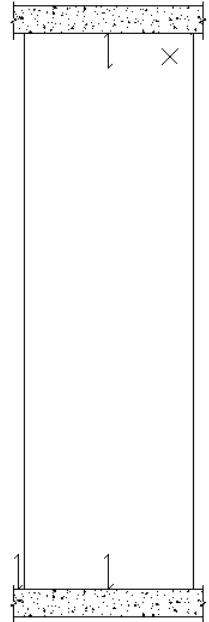

(b)

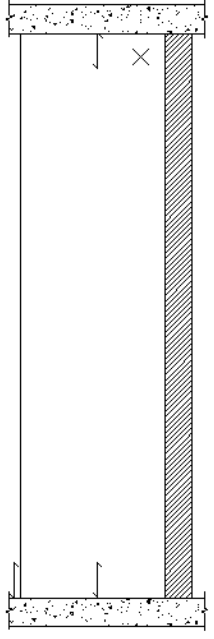

(c)

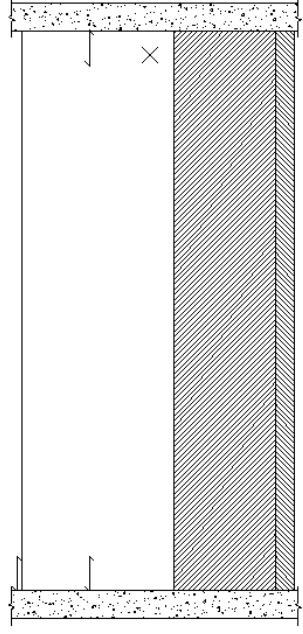

(d)

Figure 13: Potentiometer layout (a) primary wall north face (b) west return wall west face (c) north east return wall west face (d) south east return wall east face. 


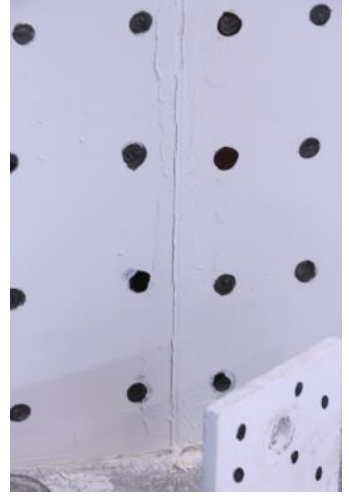

(a) Paint cracking

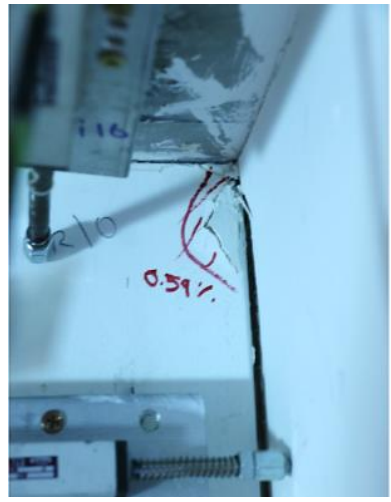

(c) Plaster cracking

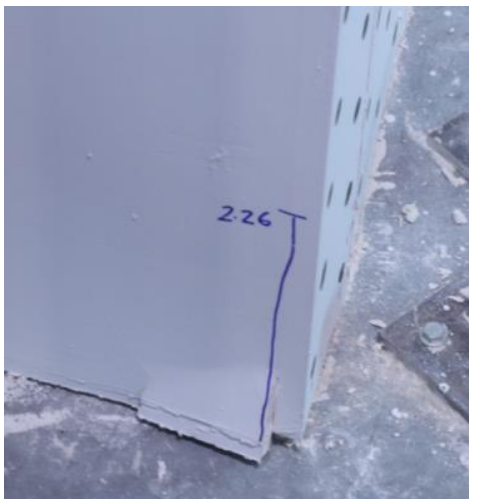

(e) Wallboard damage

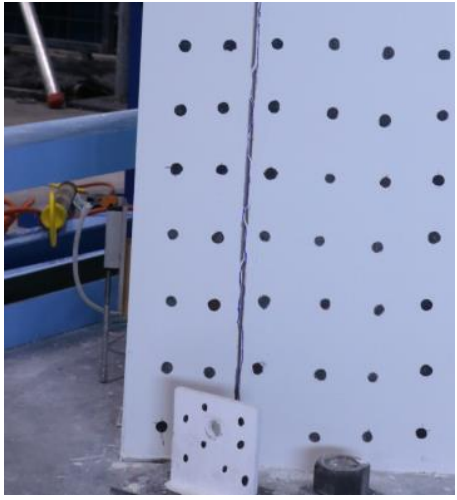

(b) Sealant de-bonding

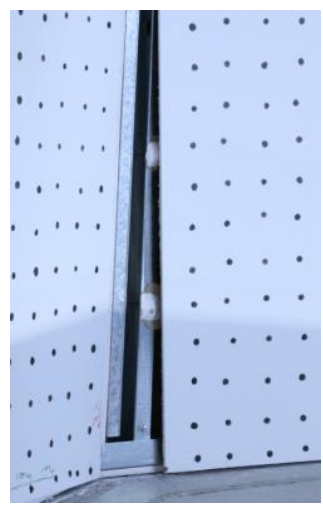

(d) Wallboard detaching

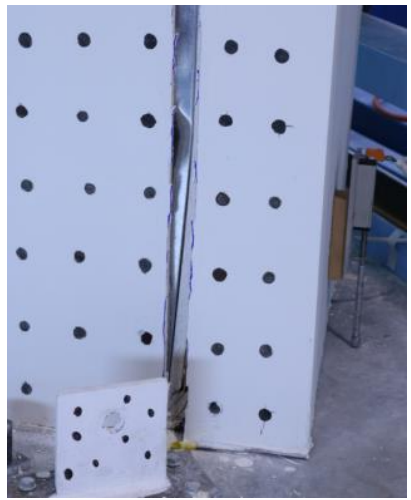

(f) Framing damage

Figure 14: Examples of specimen damage.

\section{Detailed Damage Development}

The damage progression for specimen 1 and 2 is shown in Table 5 and 6 respectively. In these tables the locations 1 to 21 shown in Figure 15 have been used when referring to damage. These locations refer to any vertical point within the area shown and represent the panels, joints between panels, and wall ends. The drift values shown in the tables refer to the in-plane drift along the different wall segments. In discussing damage progression below the in-plane drift along the long section of the wall has been used unless otherwise stated.

Both drywalls suffered damage in a similar pattern:

(1) The first signs of damage in both specimens was hairline paint cracking at the joints (DS0). For specimen 1 this occurred at locations 6 and 11 at $0.34 \%$ drift, and for specimen 2 at locations $2,6,11$, and 15 at $0.48 \%$ drift. This observation suggests that increasing the width of the joint increases the drift at which the paint along the joints remains undamaged.

(2) The next form of damage to initiate was separation of the gap filling material (DS1a). For specimen 1 this occurred at locations 6,11 , and 15 at $0.48 \%$ drift, and for specimen 2 at locations 2, 6, 11, and 15 at $0.67 \%$ drift.

(3) The third form of damage to initiate was cracking of the plaster (DS1b) and paint along the trims at joints and edges. For specimen 1 this occurred at location 10 at $0.48 \%$ drift, and for specimen 2 at several locations $(1,11,12,16,17,20$, and 21) at $0.94 \%$ drift. The design drifts at which the gaps close are $0.37 \%$ and $0.91 \%$ for specimens 1 and 2 respectively. Thus, plaster damage initiates very soon after the anticipated drift capacity is reached, and the equation used to predict the formation of DS1 provided a close prediction in specimen 1 and specimen 2 . Sealant debonding occurred simultaneously with plaster cracking in specimen 1 at $0.37 \%$ drift, but in specimen 2, sealant 


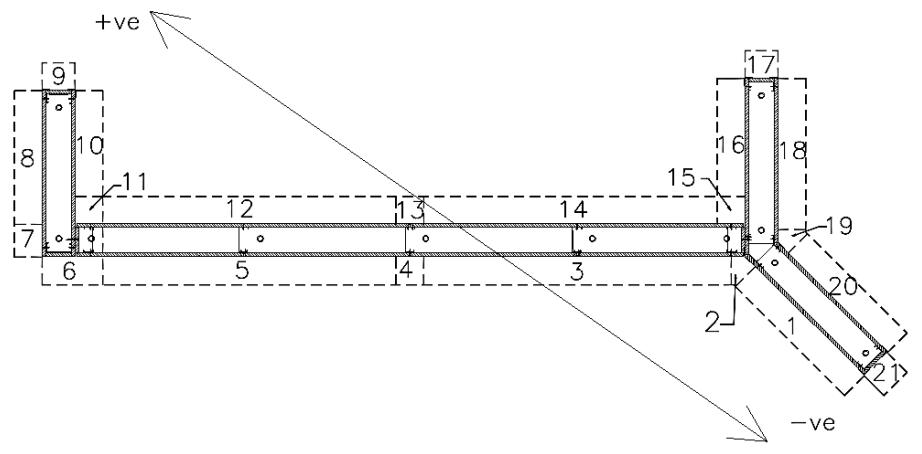

Figure 15: Reference locations for damage observations.

Table 5: Specimen 1 damage progression.

\begin{tabular}{|c|c|c|c|c|c|c|c|c|c|c|}
\hline & STEP & 8 & 9 & 10 & 11 & 12 & 13 & 14 & 15 & 16 \\
\hline \multirow{4}{*}{ 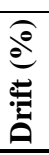 } & loading dir. & 0.42 & 0.59 & 0.82 & 1.15 & 1.62 & 2.27 & 3.17 & 4.44 & 6.21 \\
\hline & $45^{\circ}$ wall & 0.41 & 0.58 & 0.81 & 1.13 & 1.60 & 2.23 & 3.12 & 4.37 & 6.12 \\
\hline & $90^{\circ}$ walls & 0.24 & 0.34 & 0.47 & 0.66 & 0.93 & 1.30 & 1.82 & 2.55 & 3.56 \\
\hline & long wall & 0.34 & 0.48 & 0.67 & 0.94 & 1.33 & 1.86 & 2.60 & 3.64 & 5.09 \\
\hline \multirow{21}{*}{ 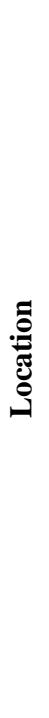 } & 1 & - & - & $1 b$ & - & - & $2 a$ & - & - & - \\
\hline & 2 & - & - & - & $1 \mathrm{a}$ & $1 b$ & - & $2 \mathrm{a}$ & - & $1 \mathrm{c}$ \\
\hline & 3 & - & - & - & - & - & - & - & $1 b$ & - \\
\hline & 4 & - & - & - & - & - & - & - & - & - \\
\hline & 5 & - & - & - & - & - & - & - & - & - \\
\hline & 6 & 0 & $1 \mathrm{a}$ & - & $2 b$ & - & - & $1 b, 2 a, 3$ & - & - \\
\hline & 7 & - & - & - & - & $1 \mathrm{~b}$ & - & - & - & - \\
\hline & 8 & - & - & - & - & $1 \mathrm{~b}$ & - & - & - & - \\
\hline & 9 & - & - & - & $1 b$ & - & - & - & - & $2 a$ \\
\hline & 10 & - & - & - & $1 b, 2 a$ & - & - & - & - & $1 \mathrm{c}$ \\
\hline & 11 & 0 & $1 \mathrm{a}, 1 \mathrm{~b}$ & - & $2 \mathrm{a}$ & - & $2 b$ & 3 & - & $1 \mathrm{c}$ \\
\hline & 12 & - & - & - & - & - & $1 b$ & - & - & $1 \mathrm{c}$ \\
\hline & 13 & - & - & - & - & - & - & - & - & - \\
\hline & 14 & - & - & - & - & - & - & - & - & - \\
\hline & 15 & - & $0,1 \mathrm{a}$ & $1 \mathrm{~b}$ & $2 a$ & - & - & - & - & - \\
\hline & 16 & - & - & - & $1 b$ & - & - & $2 \mathrm{a}$ & - & - \\
\hline & 17 & - & - & - & $1 b$ & - & - & - & - & $2 \mathrm{a}$ \\
\hline & 18 & - & - & - & - & - & - & $1 b$ & $2 \mathrm{a}$ & - \\
\hline & 19 & - & - & 0 & - & - & - & $1 b$ & - & $2 \mathrm{a}$ \\
\hline & 20 & - & - & - & $1 b, 2 a$ & - & - & - & - & - \\
\hline & 21 & - & - & - & $1 \mathrm{~b}, 2 \mathrm{a}$ & - & - & - & - & 3 \\
\hline
\end{tabular}

Table 6: Specimen 2 damage progression.

\begin{tabular}{|c|c|c|c|c|c|c|c|c|c|c|}
\hline & STEP & 8 & 9 & 10 & 11 & 12 & 13 & 14 & 15 & 16 \\
\hline \multirow{4}{*}{ 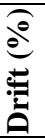 } & loading dir. & 0.42 & 0.59 & 0.82 & 1.15 & 1.62 & 2.27 & 3.17 & 4.44 & 6.21 \\
\hline & $45^{\circ}$ wall & 0.41 & 0.58 & 0.81 & 1.13 & 1.60 & 2.23 & 3.12 & 4.37 & 6.12 \\
\hline & $90^{\circ}$ walls & 0.24 & 0.34 & 0.47 & 0.66 & 0.93 & 1.30 & 1.82 & 2.55 & 3.56 \\
\hline & long wall & 0.34 & 0.48 & 0.67 & 0.94 & 1.33 & 1.86 & 2.60 & 3.64 & 5.09 \\
\hline \multirow{21}{*}{ } & 1 & - & - & - & $1 b$ & - & - & $2 \mathrm{a}$ & - & - \\
\hline & 2 & - & 0 & $1 \mathrm{a}$ & - & - & - & $2 b$ & - & $1 \mathrm{c}$ \\
\hline & 3 & - & - & - & - & - & - & - & - & $1 b, 1 c$ \\
\hline & 4 & - & - & 0 & - & $1 \mathrm{a}$ & - & $2 b$ & - & - \\
\hline & 5 & - & - & - & - & - & - & - & - & $1 b$ \\
\hline & 6 & - & 0 & $1 \mathrm{a}$ & - & - & - & $2 b$ & $2 a, 3$ & $1 \mathrm{c}$ \\
\hline & 7 & - & - & - & - & - & $1 b$ & $2 \mathrm{a}$ & 3 & - \\
\hline & 8 & - & - & - & - & - & $1 b$ & $2 \mathrm{a}$ & - & - \\
\hline & 9 & - & - & - & - & $1 b$ & - & - & 3 & $2 \mathrm{a}$ \\
\hline & 10 & - & - & - & - & - & $1 b, 2 a$ & - & - & - \\
\hline & 11 & - & 0 & $1 \mathrm{a}$ & $1 b$ & - & - & $2 b$ & $2 a, 3$ & - \\
\hline & 12 & - & - & - & $1 \mathrm{~b}$ & - & - & $2 \mathrm{a}$ & - & - \\
\hline & 13 & - & - & 0 & - & $1 \mathrm{a}$ & - & $2 b$ & - & - \\
\hline & 14 & - & - & - & - & - & - & $1 b, 2 a$ & - & - \\
\hline & 15 & - & 0 & $1 \mathrm{a}$ & - & $1 b$ & - & $2 b$ & - & - \\
\hline & 16 & - & - & - & $1 b$ & - & - & - & $2 \mathrm{a}$ & - \\
\hline & 17 & - & - & - & $1 \mathrm{~b}$ & - & - & - & $2 a$ & - \\
\hline & 18 & - & - & - & - & - & - & $1 b$ & $2 a$ & - \\
\hline & 19 & - & - & - & - & - & - & $1 b$ & $2 \mathrm{a}$ & - \\
\hline & 20 & - & - & - & $1 b$ & - & - & $1 b, 2 a$ & - & - \\
\hline & 21 & - & - & - & $1 \mathrm{~b}$ & - & - & $2 a$ & - & - \\
\hline
\end{tabular}


debonding occurred at $0.67 \%$ drift before plaster cracking at $0.94 \%$. Therefore, the prediction for DS1 appears to work for plaster cracking, but not for debonding of the gap filler. Thus, it can be inferred that using sealant will reduce the drift at the onset of DS1.

(4) For specimen 1, wallboard damage (DS2a) initiated at locations $10,11,15$, and 21 at $0.94 \%$ in-plane drift, and for specimen 2 at location 10 at $1.86 \%$ in-plane drift. The predicted lower bound at which damage to wallboard would occur was $0.58 \%$ and $1.74 \%$ drift for specimens 1 and 2 respectively. This approximation does not appear to provide a precise estimate of when wallboard damage will initiate, but it did provide a lower bound in both cases.

The rotation of the main wall section was recorded throughout the test. As the gap between the lining and the top floor was $\sim 5$ $\mathrm{mm}$, the expected maximum rotation of the linings before crushing occurs could be estimated as $(5 \mathrm{~mm} / 2410 \mathrm{~mm}) \mathrm{x}$ $100 \%$, which corresponds to $0.21 \%$ radians. Figure 16a shows that for specimen 1 crushing of the linings should begin at step 11 , at which the rotation is a maximum of $0.16 \%$ radians. This was confirmed as plasterboard crushing was observed at location 6 (Table 5) at step 11. This is earlier than anticipated however this disparity may be attributed to small variations in the gap size between the linings and the top floor. Figure 16b shows that the rotation was predominantly fully recovered at equilibrium until larger displacement cycles.
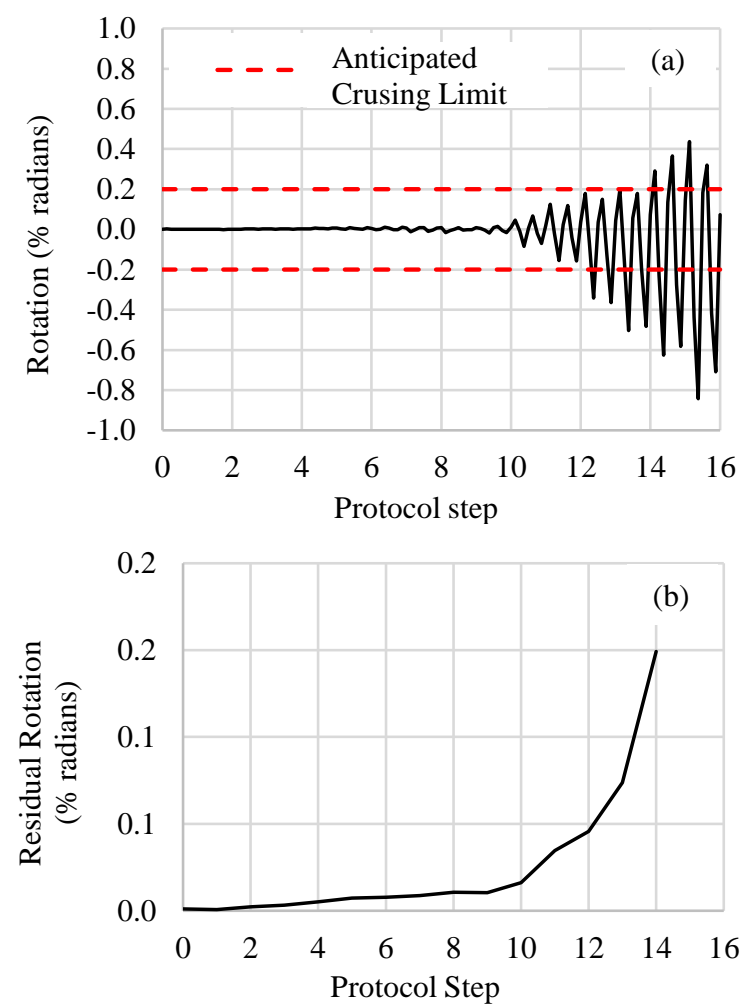

Figure 16: Specimen 1 potentiometer readings to record rotation: (a) peak excursions during each step and (b) residual rotation after each step.

(5) The residual gap size developing at the junction between the main wall and the returns was recorded. Figure 17a and 18a show the sliding of the linings during each cycle and Figure 17b and $18 \mathrm{~b}$ show the residual sliding displacement of the linings at the end each cycle. For specimen 1, Figure 17b shows that the residual gap exceeded the limiting size for fire performance after step 11, and for specimen 2, Figure 18b indicates that there was negligible residual sliding and thus a residual gap should not have developed. However, it was observed that the bottom track within the North West return wall (location 7) had bent such that at loading step 14 a residual gap was present even though the wallboards had returned to their original position as shown by Figure 18b. It can be seen in Figure 18 that the sliding of the linings occurred primarily in the positive direction. This is attributed to the bending of the bottom track at location 7 , which will have reduced the sliding force imposed upon the linings when displaced in the negative direction.
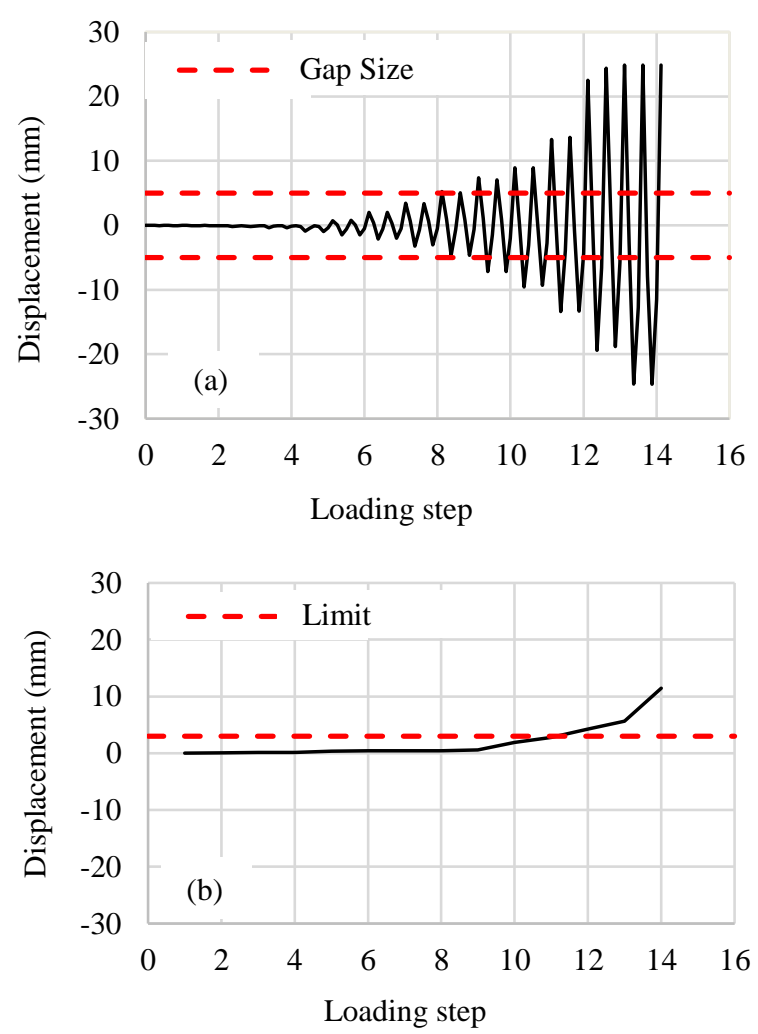

Figure 17: Specimen 1 potentiometer readings to record sliding: (a) peak excursions during each step and (b) residual displacement after each step.

Assuming both the return walls and the primary wall behave as rigid bodies, a gap forms at the junction of the main wall and return wall as explained in Figure 19 for specimen 1. This mechanism shows that the linings and studs slide as the gaps on either side of the wall close. However, when the relative displacement returns to equilibrium, they will not re-centre. The sliding of the main wall section was recorded by potentiometers. It can be seen in Figure 17a that at loading step 9, which corresponds to $0.48 \%$ drift and a displacement of 11.5 $\mathrm{mm}$, the wall slides approximately half of the total gap size $(5 \mathrm{~mm})$ in each direction. This is how the wall would be expected to behave if Figure 18 is a correct explanation; however, Figure 17b shows that the gap re-centres after step 9, and only begins to increase in size at larger cycles, until at step 11 , corresponding to $0.94 \%$ in-plane drift, the gap is large enough such that the fire performance is hindered. This initial re-centring behaviour may be attributed to the presence of the gap filling material at the junctions. This is supported by the observation that separation of the gap filling material occurs at step 9 after which a gap begins to develop. Two solutions are possible to address the problem of residual gap development: (1) provide additional vertical strips of gypsum lining between adjacent walls and the vertical steel tracks such that a larger gap can be accommodated before the fire performance is hindered or (2) provide a pivot point to force the linings to return to their original position at the end of a loading cycle. The anticipated effect of introducing a pivot to the system is shown and explained in Figure 20. 

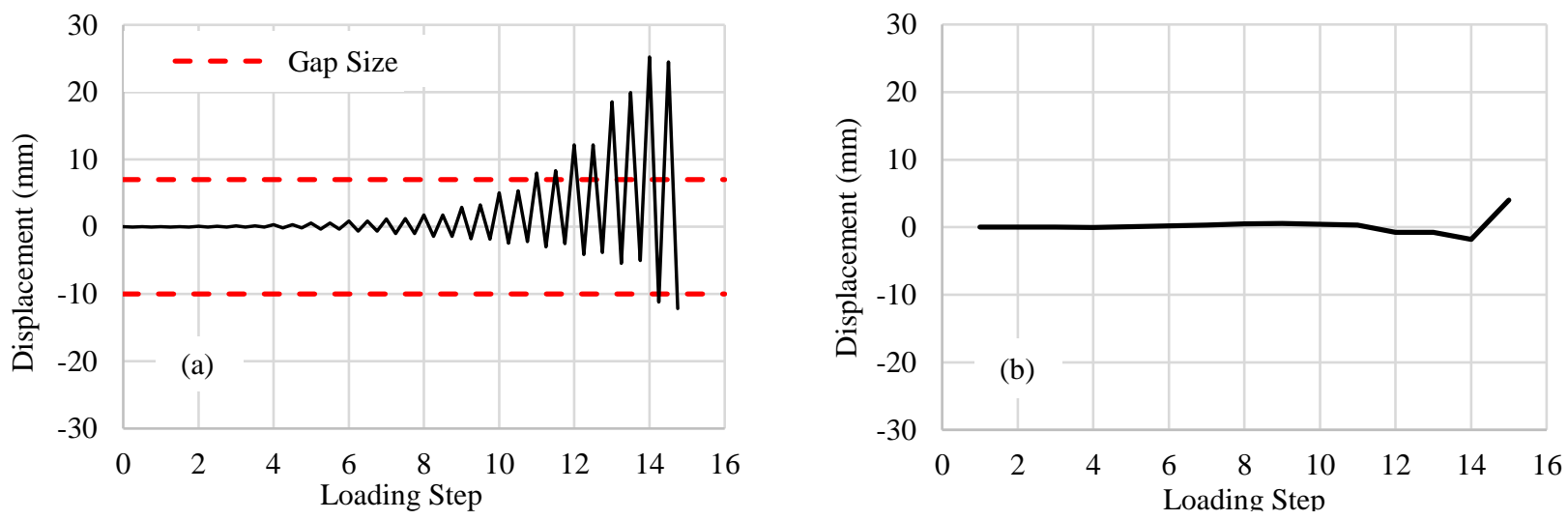

Figure 18: Specimen 2 potentiometer readings to record sliding: (a) peak excursions during each step and (b) residual displacement after each step.
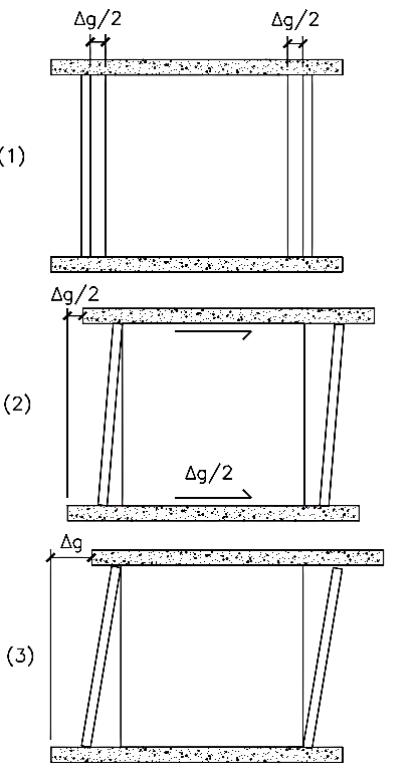

Figure 19: Explanation of residual gap formation for a loading sequence of one peak excursion:

(1) Initial condition, (2) lateral displacement of $\Delta \mathrm{g} / 2$ imposed on slab and gap on left closes, (3) lateral displacement of $\Delta g$ imposed on slab, linings slide $\Delta \mathrm{g} / 2$, and gap on right also closes, (4) lateral displacement of slab reduced back to $\Delta \mathrm{g} / 2$, (5) lateral displacement of slab reduced to zero and residual displacement in wall remains.

(6) The final form of damage to occur was framing damage (DS3). The first observable form of framing damage in specimen 1 was hinging of the vertical steel tracks at locations 6 and 11 at $2.6 \%$ drift. This was able to be observed as the gap between the linings and the return wall had grown such that the underlying framing was visible. For specimen 2, damage at locations 6 and 11 was also observed where the flanges of the vertical steel tracks were bent out. Additionally, bottom track damage was observed at locations 7 as the plasterboard had pushed the track flanges flat at this location, and at location 9 where the bottom track flanges were bent in.

\section{Force Displacement Behaviour}

The hysteretic response for the specimens is shown in Figure 21 and the maximum loads presented in Table 7. The general
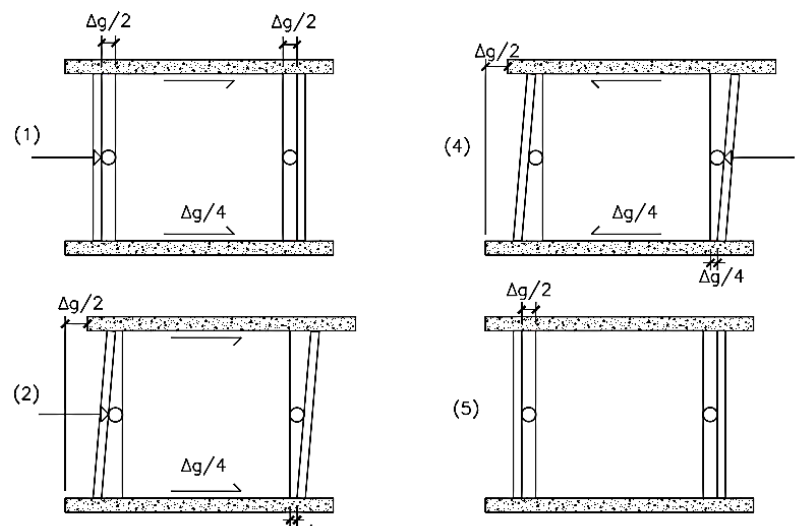

(2)

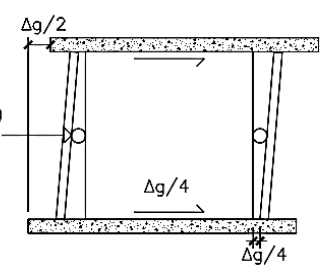

(3)

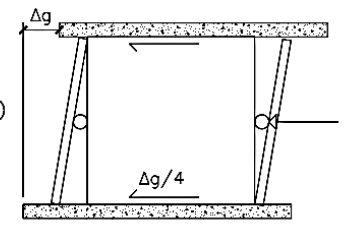

Figure 20: Explanation of the effects of introducing a pivot at mid-height on the formation of a residual gap, for a loading sequence of one peak excursion: (1) Initial condition, (2) lateral displacement of $\Delta g / 2$ imposed on slab and linings slide $\Delta \mathrm{g} / 4$, (3) lateral displacement of $\Delta \mathrm{g}$ imposed on slab and linings slide $\Delta \mathrm{g} / 4$, (4) lateral displacement of slab reduced back to $\Delta \mathrm{g} / 2$ and linings slide back $\Delta g / 4$, (5) lateral displacement of slab reduced to zero and residual linings slide $\Delta \mathrm{g} / 4$ to return to initial position.

pattern of behaviour was that the load and displacement started at zero but thereafter the load was non-zero at zero displacement. This is due to inelastic behaviour. When loaded in the positive direction, the walls had less capacity in all cases. This asymmetric behaviour may be due to a couple of reasons: (1) The asymmetry of the specimens, and (2) bias in the loading; as the loading is first applied in the positive direction for each step the specimen will damage in the first cycle leaving less capacity in the specimen when the loading is reversed. However, as the positive direction had less capacity for both specimens, also under subsequent cycles to the same drift demand, the geometry of the specimen must have been the main factor producing this asymmetric response. The orientation of the specimen to the loading direction is as shown in Figure 9a, where $\theta$ is $35^{\circ}$. 
Table 7: Maximum load from tests.

\begin{tabular}{ccccc} 
& \multicolumn{2}{c}{ Negative Direction } & \multicolumn{2}{c}{ Positive Direction } \\
\hline Specimen & $\begin{array}{c}\text { Max Load } \\
(\mathbf{k N})\end{array}$ & $\begin{array}{c}\text { Drift } \\
(\boldsymbol{\%})\end{array}$ & $\begin{array}{c}\text { Max Load } \\
(\mathbf{k N})\end{array}$ & $\begin{array}{c}\text { Drift } \\
(\boldsymbol{\%})\end{array}$ \\
\hline 1 & 12.89 & 3.13 & 8.68 & 2.08 \\
2 & 12.92 & 6.18 & 9.91 & 5.70 \\
\hline
\end{tabular}

The dissipated energy and equivalent viscous damping at each amplitude of loading was determined. This information may be useful for those interested in undertaking refined analyses on partition walls. The energy absorbed by the specimen is defined as the area within the force-displacement curve. The hysteretic curves shown in Figures 21a and 21b were integrated using the trapezium method for each increment in data. The energy dissipated in the two cycles of loading was averaged to attain the average energy dissipation at each amplitude. The equivalent viscous damping was determined at each cycle according to equation 3 . Where $A_{h}$, is the area within the hysteretic loop, $F_{m}$ is the force at the displacement of $\Delta m$, the maximum imposed displacement in the cycle. Applying this equation led to the values in Figure 22.

$\xi_{\text {hyst }}=\frac{A_{h}}{2 \pi F_{m} \Delta_{m}}$

\section{Comparison of Results with Previous Studies}

Table 8 shows a comparison of the predicted versus observed damage in specimens incorporating seismic gaps from previous studies. In assessing these results, it is important to note how damage observations were made. As it is impractical to take detailed assessments of damage continuously, the damage

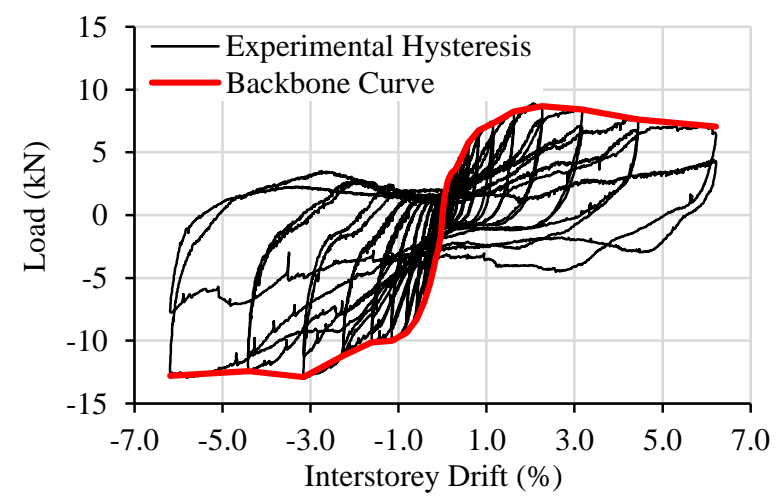

observations are made at discrete points in the loading history, typically at the end of each loading step. Thus, the accuracy of damage observations will have an error proportional to the step size of the loading protocol. Note that for the studies done by Lee et al. [13] and Magliulo et al. [19] the size of the vertical gap between linings and the support frame was not provided in their report; therefore, predictions could not be made for DS2.

Table 8 shows that the prediction for the onset of DS1 based upon the size of the horizontal gaps is accurate across all five experimental tests. While there is an apparent discrepancy between the predicted and observed drift at onset of DS1 for the specimens tested by Tasligedik et al. [20] this can be accounted for by the step size of the loading protocol. The loading protocol used by Tasligedik et al. [20] applied a drift of $1.50 \%$ at step 10 and $2.00 \%$ at step 11 . DS1 was therefore observed following the completion of step 11. This implies that DS1 was triggered between $1.50 \%$ and $2.00 \%$ drift, which is the range wherein the predicted value lies. The prediction for the onset of DS2 was in all cases below the observed drift. For the specimens tested by Tasligedik et al. [20] the exact drift DS2 initiated is not known as the tests were only run to $2.50 \%$ drift, but it can be stated that for at least one of the specimens the wall had greater capacity for DS2 than that predicted. Although the prediction for specimen 2 in this paper significantly underestimated the onset of DS2, the equation did provide a lower bound in all cases albeit a conservative one.

There were a number of differences between specimen designs and method of load application for the four previous studies shown in Table 8. While the specimen designs in Lee et al. [13], Magliulo et al. [19], Tasligedik et al. [20], and Pali et al. [22] all incorporated seismic gaps and were constructed such that the lining and internal framing was free to slide within the tracks, there were some variations.

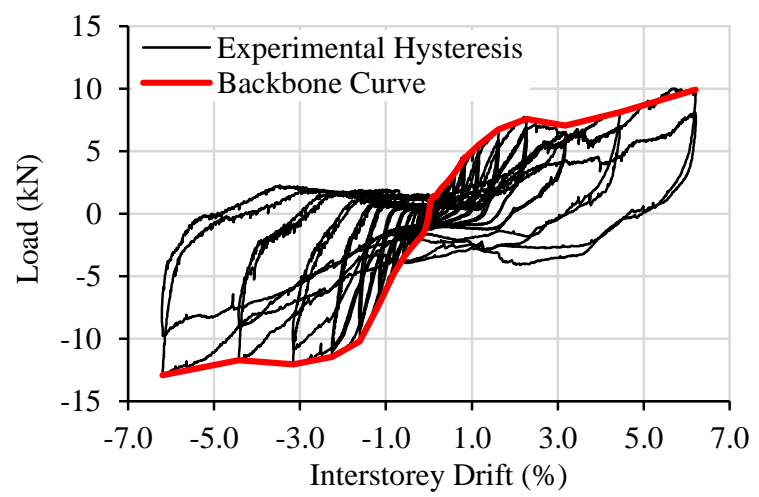

Figure 21: Left: Specimen 1 hysteresis; Right: Specimen 2 hysteresis.
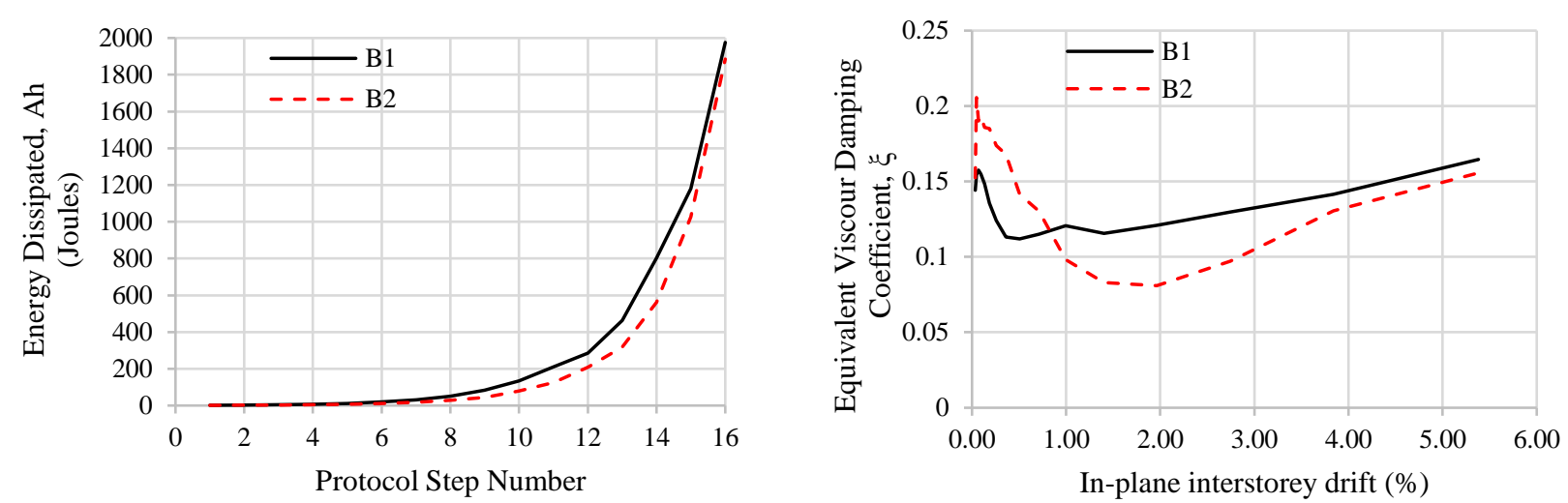

Figure 22: Left: Energy dissipation at each amplitude of loading; Right: Equivalent viscous damping coefficient (Equation 3). 
Table 8: Comparison of predicted and observed damage progression in previous studies.

\begin{tabular}{|c|c|c|c|c|c|c|c|}
\hline Author & $\begin{array}{c}\text { Lee et al. } \\
\quad[13]\end{array}$ & $\begin{array}{c}\text { Magliulo et al. } \\
{[19]}\end{array}$ & Taslige & al. [20] & Pali et al. [22] & \multicolumn{2}{|c|}{ This Paper } \\
\hline \multicolumn{8}{|c|}{ Dimensions } \\
\hline $\mathbf{h}_{\mathbf{c}}(\mathbf{m m})$ & 2800 & 2680 & 2550 & 2550 & 2700 & 2405 & 2405 \\
\hline $\mathbf{L}(\mathbf{m m})$ & 3950 & 2270 & 1200 & 3400 & 2400 & 2415 & 2410 \\
\hline$\Delta h(\mathbf{m m})$ & 30 & 16 & 40 & 40 & 40 & 22 & 9 \\
\hline$\Delta v(\mathbf{m m})$ & - & - & 26 & 26 & 20 & 10 & 5 \\
\hline \multicolumn{8}{|l|}{ Prediction } \\
\hline DS1 (\%) & 1.07 & 0.60 & 1.57 & 1.57 & 1.48 & 0.91 & 0.37 \\
\hline DS2 (\%) & - & - & 3.73 & 2.33 & 2.31 & 1.74 & 0.58 \\
\hline \multicolumn{8}{|c|}{ Observation } \\
\hline DS1 (\%) & 1.0 & 0.58 & 2.0 & 2.0 & 1.53 & 0.94 & 0.48 \\
\hline DS2 (\%) & 1.5 & 0.98 & $>2.5$ & $>2.5$ & $2.47 *$ & 1.86 & 0.94 \\
\hline
\end{tabular}

*DS2 for this case is referring to the onset of corner crushing in the gypsum wallboard noting that the Pali et al. [22] definition for DS2 includes failure of panel-to-frame fixings and collapse of dowels, which was observed at smaller drift levels than corner crushing. The average value has been taken between the two relevant specimens tested by Pali et al. [22] (specimens \#7 and \#8).

The differences included variations in stud size, spacing, and material (including timber and steel); track size; fastener type and spacing; and plasterboard thickness and number of layers. In addition, all of the seismic gap systems tested in these studies were tested with structural elements at the wall ends. The studies by Lee et al. [13], Tasligedik et al. [20], and Pali et al. [22] used quasi-static cyclic loading protocols applied in-plane to the partition wall specimens, albeit with different protocols, and the study by Magliulo et al. [19] used dynamic loading. Despite the differences between the specimen designs from the previous studies and the specimens tested in this paper, it can be seen from Table 8 that using Equation 1 to predict the drift at the onset of DS1 is accurate in all cases. It is of particular interest that although for the specimens tested in this study loading was applied at an angle of $35^{\circ}$ to the long wall section and the specimen was configured with return walls in a y-shape with one $45^{\circ}$ return wall, Equation 1 still provided an accurate prediction for the drift in-plane to the wall at the onset of DS1. Therefore, for the specimens tested in this study, out-of-plane displacements or return wall configuration did not appear to significantly impact the onset of DS1b (plaster cracking).

\section{CONCLUSIONS}

Two y-shaped partition wall specimens with seismic gaps aligned at $35^{\circ}$ to the direction of loading were subjected to quasi-static cyclic testing: one steel stud specimen with horizontal gaps at the wall ends totalling $9 \mathrm{~mm}$; and one timber stud specimen with horizontal gaps totalling $22 \mathrm{~mm}$. The seismic gaps in the specimens were half-filled with an acrylic gap-filler. In addition to providing drift capacities, the forcedisplacement behaviour has been reported, and the energy dissipation computed.

The main findings of the experimental tests are as follows:

- An equation was used to predict the formation of DS1. This equation provided an accurate estimate for DS1 in specimen 1 where plaster cracking and debonding of the gap filler material occurred simultaneously. For specimen 2 the equation accurately estimated the onset of plaster cracking but not debonding of the gap filler material, which initiated earlier.

- The gap filling material appeared to reduce the drift at the onset of DS1 for specimen 2. However, it had a beneficial effect on the re-centring behaviour of the linings. If a gapfilling material is not used, it is suggested that a pivot system is utilized in order to prevent residual gap development.

- An equation was proposed to predict the onset of DS2. This equation provided a lower bound for both specimens tested herein and when used to predict the results of previous experimental tests on seismic gap systems.

- For the specimens tested in this study, out-of-plane displacements imposed and return wall configuration did not appear to significantly impact the onset of plaster cracking in the specimens.

\section{ACKNOWLEDEGEMENTS}

The authors gratefully acknowledge the funding \& support offered by Ali Sahin Tasligedik; The International Collaborative Research program of the Disaster Prevention Research Institute, Kyoto University under Project Number 28W-03 (PI: Timothy Sullivan); the University of Canterbury Quake Centre; QuakeCoRE; NZ Property Council; RONDO; Winston Wallboards; Dunning Thornton Consultants; and Holmes Consulting. This project was partially supported by QuakeCoRE, a New Zealand Tertiary Education Commissionfunded Centre. This is QuakeCore publication number 0457.

\section{REFERENCES}

1 Taghavi S and Miranda E (2003). "Response Assessment of Nonstructural Building Elements". Report 2003/05. Pacific Earthquake Engineering Research (PEER) Centre, Berkley, $96 \mathrm{pp}$.

2 Khakurel S, Dhakal RP, Yeow T and Saha S (2020). "Performance group weighting factors for rapid seismic loss estimation of buildings of different usage". Earthquake Spectra, 36(3): 1141-1165. https://doi.org/10.1177/8755293019901311

3 Bradley BA, Dhakal RP, Cubrinovski M and MacRae GA (2009). "Seismic loss estimation for efficient decision making". Bulletin of the New Zealand Society of Earthquake Engineering, 42(2): 96-110. https://doi.org/10.5459/bnzsee.42.2.96-110

4 Dhakal RP, Pourali A and Saha S (2016). "Simplified seismic loss functions for suspended ceilings and drywall partitions". Bulletin of the New Zealand Society for Earthquake Engineering Special Issue on Seismic Performance of Non-Structural Elements (SPONSE), 49(1): 64-78. https://doi.org/10.5459/bnzsee.49.1.64-78 
5 Whitman RV, Hong S-T and Reed JW (1973). "Damage Statistics for Highrise Buildings in the Vicinity of the San Fernando Earthquake". Report NSF-RA-E-73-549, Massachusetts Institute of Technology Department of Civil Engineering, Cambridge, 226 pp.

6 Davies RD, Retamales R, Mosqueda G and Filiatrault A (2011). "Experimental Seismic Evaluation, Model Parameterization, and Effects of Cold-Formed SteelFramed Gypsum Partition Walls on the Seismic Performance of an Essential Facility". Technical Report MCEER-11-0005, University at Buffalo, New York, 221 pp.

7 Arifin FA (2017). "Identification of Cost-Effective Retrofit and/or Rehabilitation Strategies for Steel Buildings". Masters Thesis, University of Canterbury, Christchurch, 306 pp.

8 Dhakal RP (2010). "Damage to non-structural components and contents in 2010 Darfield earthquake". Bulletin of the New Zealand Society for Earthquake Engineering, 43(4): 404-410. https://doi.org/10.5459/bnzsee.43.4.404-410

9 Baird A, Tasligedik AS, Palermo A and Pampanin S (2014). "Seismic performance of vertical nonstructural components in the 22 February 2011 Christchurch earthquake". Earthquake Spectra, 30(1): 401-425. https://doi.org/10.1193/031013EQS067M

10 Freeman SA (1971). "Third Progress Report on Racking Tests of Wall Panels". Report JAB-99-54, University of California, Berkeley, 270 pp.

11 Rihal SS (1980). "Racking Building Tests of Non-Structural Building Partitions". Report ARCE R90-1, California Polytechnic State University, San Luis Obispo, 123 pp.

12 Adham SA, Avanessian V, Hart GC, Anderson RW, Elmlinger J and Gregory J (1990). "Shear wall resistance of lightgage steel stud wall systems". Earthquake Spectra, 6(1): 1-14. https://doi.org/10.1193/1.1585555

13 Lee TH, Kato M, Matsumiya T, Suita K and Nakashima M (2007). "Seismic performance evaluation of non-structural components: Drywall partitions". Earthquake Engineering and Structural Dynamics, 36(3): 367-382. https://doi.org/10.1002/eqe.638

14 Restrepo JI and Bersofsky AM (2011). "Performance characteristics of light gage steel stud partition walls". ThinWalled Structures, 49(2): 317-324. https://doi.org/10.1016/j.tws.2010.10.001

15 Jenkins C, Soroushian S, Rahmanishamsi E and Maragakis EM (2016). "Experimental fragility analysis of cold-formed steel-framed partition wall systems". Thin-Walled Structures, 103: 1760-1773.

https://doi.org/10.1016/j.tws.2016.02.015

16 Petrone C, Magliulo G, Lopez P and Manfredi G (2016). "Out-of-plane seismic performance of plasterboard partition walls via quasi-static tests". Bulletin of the New Zealand Society of Earthquake Engineering, 49(1): 125137. https://doi.org/10.5459/bnzsee.49.1.125-137

17 Mulligan JG, Sullivan TJ and Dhakal RP (2020). "Experimental Seismic Performance of Partly-Sliding Partition Walls". Journal of Earthquake Engineering. https://doi.org/10.1080/13632469.2020.1733139

18 Araya-Letelier G and Miranda E (2012). "Novel sliding/frictional connections for improved seismic performance of gypsum wallboard partitions". $15^{\text {th }}$ World Conference on Earthquake Engineering, 24-28 September, Lisbon, Portugal.

19 Magliulo G, Petrone C, Capozzi V, Maddaloni G, Lopez P and Manfredi G (2014). "Seismic performance evaluation of plasterboard partitions via shake table tests". Bulletin of Earthquake Engineering, 12(4): 1657-1677. https://doi.org/10.1007/s10518-013-9567-8

20 Tasligedik AS, Pampanin S and Palermo A (2015). "Low damage seismic solutions for non-structural drywall partitions". Bulletin of Earthquake Engineering, 13(4): 1029-1050. https://doi.org/10.1007/s10518-014-9654-5

21 Pali T, Bucciero B, Terracciano MT, Macillo V, Fiorino L and Landolfo R (2017). "In-plane quasi-static cyclic tests on lightweight steel drywall non-structural partition walls". celpapers, 1(2-3): 2857-2866. https://doi.org/10.1002/cepa.337

22 Pali T, Macillo V, Terracciano M, Bucciero B, Fiorino L and Landolfo R (2018). "In-plane quasi-static cyclic tests of nonstructural lightweight steel drywall partitions for seismic performance evaluation". Earthquake Engineering and Structural Dynamics, 47(6): 1566-1588. https://doi.org/10.1002/eqe.3031

23 Winstone Wallboards (2012). "GIB Fire Rated Systems". Report CBI 5113, Winstone Wallboards, Auckland, 84 pp.

24 Federal Emergency Agency (FEMA) (2007). "FEMA 461: Interim Testing Protocols for Determining the Seismic Performance Characteristics of Structural and Nonstructural Components". Washington D.C., 138 pp. 